\title{
Study on the Capacity Degradation of Bucket Foundation in Liquefied Sand Layer under Cyclic Loads
}

\author{
Chi $\mathrm{Li}^{1 *}$, Xiaobing $\mathrm{Lu}^{2}$ and Shuyun Wang ${ }^{2}$ \\ ${ }^{1}$ Inner Mongolia University of Technology, Huhhot, 010051, China \\ ${ }^{2}$ Institute of Mechanics, Chinese Academy of Science, Beijing 100190, China
}

\begin{abstract}
The capacity degradation of bucket foundation in liquefied sand layer under cyclic loads such as equivalent dynamic ice-induced loads is studied. A simplified numerical model of liquefied sand layer has been presented based on the dynamic centrifuge experiment results. The ice-induced dynamic loads are modeled as equivalent sine cyclic loads, the liquefaction degree in different position of sand layer and effects of main factors are investigated. Subsequently, the sand resistance is represented by uncoupled, non-linear sand springs which describe the sub-failure behavior of the local sand resistance as well as the peak capacity of bucket foundation under some failure criterion. The capacity of bucket foundation is determined in liquefied sand layer and the rule of capacity degradation is analyzed. The capacity degradation in liquefied sand layer is analyzed comparing with that in non-liquefied sand layer. The results show that the liquefaction degree is 0.9 at the top and is only 0.06 at the bottom of liquefied sand layer. The numerical results are agreement well with the centrifugal experimental results. The value of the degradation of bucket capacity is $12 \%$ in numerical simulating whereas it is $17 \%$ in centrifugal experiments.
\end{abstract}

Keywords: Bucket foundation, equivalent dynamic ice-induced loads, liquefaction degree, capacity degradation.

\section{INTRODUCTION}

As a newly and moving platform, bucket foundations have been extensively used in ocean engineering specially in developing marginal oil field because of their simplicity, reliability and cost savings. Despite several studies about static capacity and stability in subsiding for bucket foundations have been done [1-4], the long-term bearing capacity of bucket foundation under cyclic loads has not clarified. Several approaches to evaluating soil bearing capacities under cyclic loads [5-9] supply good reference for us. Wang et al. [10-13] presented a method to determine saturated soft clay's cyclic strength based on cyclic triaxial experiment, and made some theoretic and large-scale model experimental studies about bearing capacity of bucket foundation under cyclic loads on soft clay layer. A dynamic centrifuge experiment is carried to study the liquefied or softened character of sand layer around bucket foundation under dynamic load, and to analyze influencing factors of liquefied area expanding [1416]. Sum up the research results indicate that the liquefaction appears around bucket foundation in the sand layer under wave loads or dynamic ice-induced loads in marine environment, leading to the bearing capacity degradation to some degree for bucket foundation with sand layer liquefaction growing.

Wave loads or ice-induced dynamic loads cause the foundation to be subjected to sine cyclic loads. When cyclic loads act on the upper structures of a platform, the sand layer surrounding the bucket foundation will be perturbed by the

* Address correspondence to this author at Inner Mongolia University of Technology, Huhhot, 010051,China; Tel: 86-0471-6576543; Fax: 86-04716575700; Email: tjdxlch2003@126.com loads transmitted from the bucket. Under cyclic loads, the excess pore pressure in the saturated sand layer may accumulate and the sand layer may even liquefy. The resistance of the sand which has partial liquefaction but not liquefied entirely descends in certain level, but not bankrupt. At this time, with the strength descend of the liquefied sand layer, the bearing capacity of bucket foundation will degrade gradually. According to the character of Bohai marine environment in China, take ice-induced dynamic loads as an example, the degradation rule of bucket foundation's bearing capacity is studied in the sand layer that has partial liquefaction but not liquefied entirely under equivalent dynamic iceload through numerical simulation. Analyzing the relation between the liquefaction degree of sand layer and the degradation rule of bucket foundation's bearing capacity, and offers theoretic direction to design and use of bucket foundation in marine engineering.

\section{INTRODUCTION OF THE CENTRIFUGE EXPERI- MENT}

\section{Preparation of Centrifugal Model}

Centrifugal experiments are carried out in the $50 \mathrm{~g}$-t geotechnical centrifuge in Tsinghua University, the maximum centrifugal acceleration is $250 \mathrm{~g}$. The allowable maximum capacity is $300 \mathrm{~kg}$ while the centrifugal acceleration is $100 \mathrm{~g}$. The inner size of the model box is $600 \mathrm{~mm} \times 350 \mathrm{~mm} \times 350 \mathrm{~mm}$. The fine sand is adopted in experiments whose specific gravity is 2.69 , the average diameter is $0.14 \mathrm{~mm}$, and the permeability coefficient is $5 \times 10^{-4} \mathrm{~cm} / \mathrm{s}$. The layout of centrifugal model is shown in Fig. (1). The model bucket foundation is made of steel. The inner and outer diameters of the bucket are $60 \mathrm{~mm}$ and $62 \mathrm{~mm}$, respectively. The net depth of the 
bucket is $70 \mathrm{~mm}, 72 \mathrm{~mm}$, and $48 \mathrm{~mm}$, the thickness of the cap is $2 \mathrm{~mm}$. Because the height of exciting pole that connected with the exciter was fixed, so a thin walled sliding chute was fixed on the thin steel pipe, on one end of the connection between the exciting pole and the top steel pipe had a steel ball, it could move upper and lower in sliding chute, and rotate in the vertical plane around horizontal axis. So, the exciting pole can not be jammed while the foundation subsiding. A horizontal and a vertical displacement sensor were arranged on top of the bucket foundation, and two vertical displacement sensors were arranged around the bucket to measure the subsiding on the different point of sand.

Ten PDCR81 type pore water pressure sensors that were imported from British DRUCK Company were buried in sand during the preparation of sand samples (non-fixed, can deform with the sand subsiding), their arrangements are shown in Figs. 2(a,b), the vertical and horizontal interval of each PPT was $1 \mathrm{~cm}$. The distance between the head of the sensor and the nearest bucket lateral wall was $2 \mathrm{~mm}$. The water depth above mud surface was $1 \mathrm{~cm}$, No.17 and No.1 PPT were $2 \mathrm{~cm}$ below water surface, No.17, 10, 15 and No.7 were away from bucket lateral wall $2 \mathrm{~mm}$, the distance between per two horizontal pore pressure sensors was $5 \mathrm{~mm}$, and the distance between per two vertical pore pressure sensors was $2 \mathrm{~cm}$, No.11 and No.16 sensors were $4 \mathrm{~cm}$ and $8 \mathrm{~cm}$ respectively below water surface. The purpose that it had two arrangement forms was to measure the change of pore water pressure in vertical and horizontal directions.

In order to ensure good repeatability and uniformity, $21 \mathrm{~cm}$ silty sand was divided into 5 layers; every layer was compacted by hand softly, and controlled by dry density. The saturation of samples was carried out by water seepage from bottom to top of the model slowly. After the laying of sand completed and the water surface was over the sand, saturated the sand with the vacuum pump, pumped 38 hours continuously. The saturation can reach $95 \%$ ultimately.

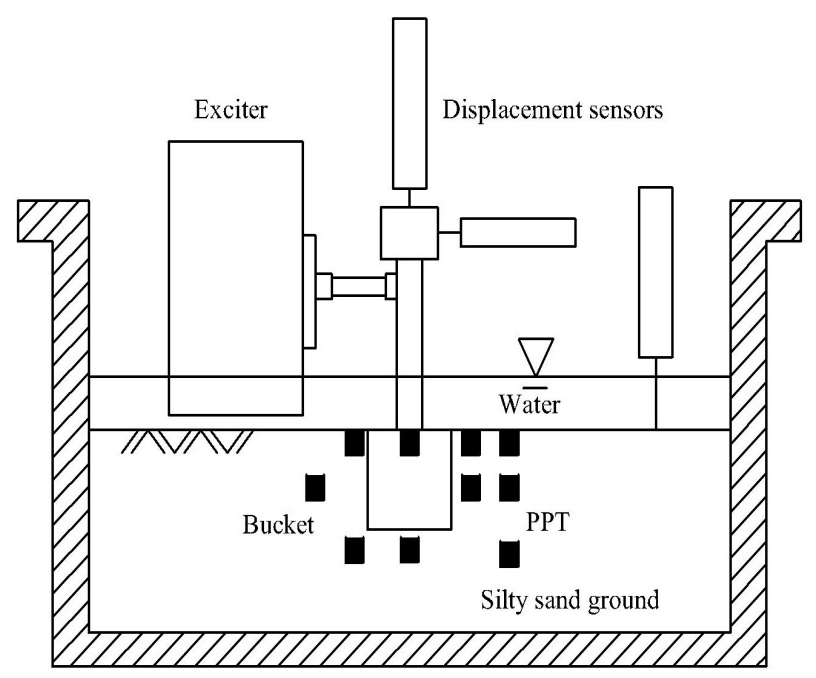

Fig. (1). Layout of centrifugal model.

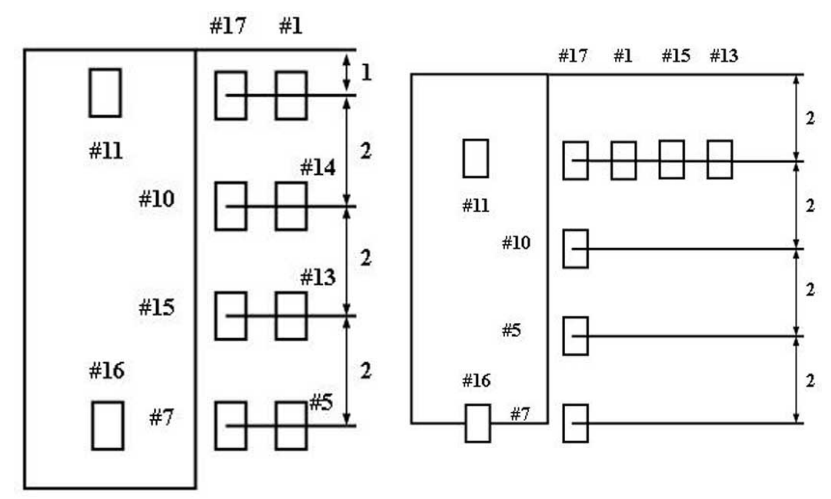

(a)

Fig. (2). Two arrangement forms of PPT.

Preparing ice in centrifuge and impelling it move was very difficult, so, in this experiment, the equivalent dynamic ice-induced load imposed on the bucket foundation. The onsite measured response frequency of the platform under the dynamic ice-induced load action in Bohai area is $0.8 \sim 1.2 \mathrm{~Hz}$, so the frequency of the equivalent dynamic ice-induced load adopted $1.0 \mathrm{~Hz}$ in centrifuge experiment. Because the purpose of this study is obtaining the bucket foundation's response law under dynamic ice-induced load, and offering reference to theoretic and numerical analysis, not for simulating the special conditions of somewhere actually. So the load in this experiment is simplified to sine-wave dynamic load, but adopted the silty sand that was similar with the onsite ground.

The position that the vibration exciter loading was away from the bucket top $6.5 \mathrm{~cm}$ before consolidation, this relative position would increase with the bucket's subsiding. Fig. (3) shows the force carried on the bucket foundation in the beginning stage and the last stage. From the Fig. (3) we can see, the bearing capacity of the bucket decreases about $17 \%$ after the top sand liquefied.

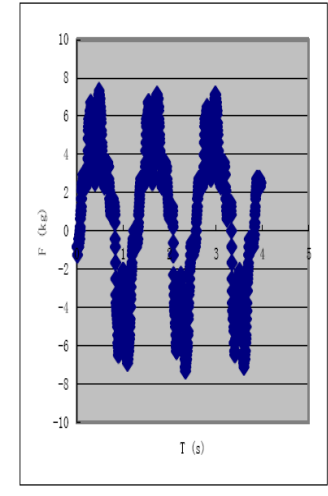

(a) at first stage

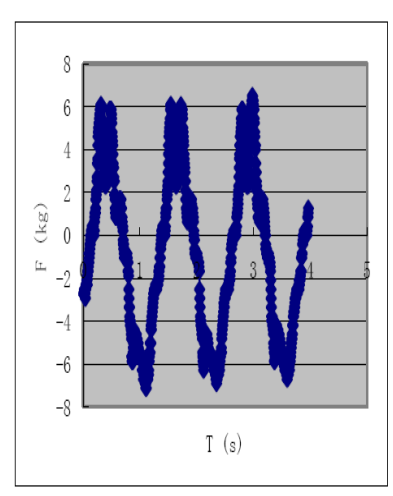

(b) at last stage

Fig. (3). Dynamic ice-induced load acts on the bucket.

\section{Results of Centrifugal Experiment}

The experimental results show that the excess pore pressure increases quickly in the beginning, and then decreases gradually. In the beginning, the small permeability leads to the accumulation of pore pressure in short amount of time. 
However, with the increase of excess pore pressure, the strength of sand layer decreases and even the sand layer liquefies, then the percolation increases and the sand layer consolidates, the excess pore water drains gradually. Accordingly, the pore pressure decreases.

The liquefaction degree $\left(F_{l}\right)$ is defined as the ratio of the excess pore water pressure $(u)$ to the initial vertical effective stress $\left(\sigma^{\prime}\right)$, e.g. $F_{l}=u / \sigma^{\prime}$.

Liquefaction degree varies with the amplitude of dynamic load shows in Fig. (4). It is shown that the excess pore pressure rises more quickly while the load amplitude increases under the same initial vertical effective stress, and the liquefaction degrees growing obviously.

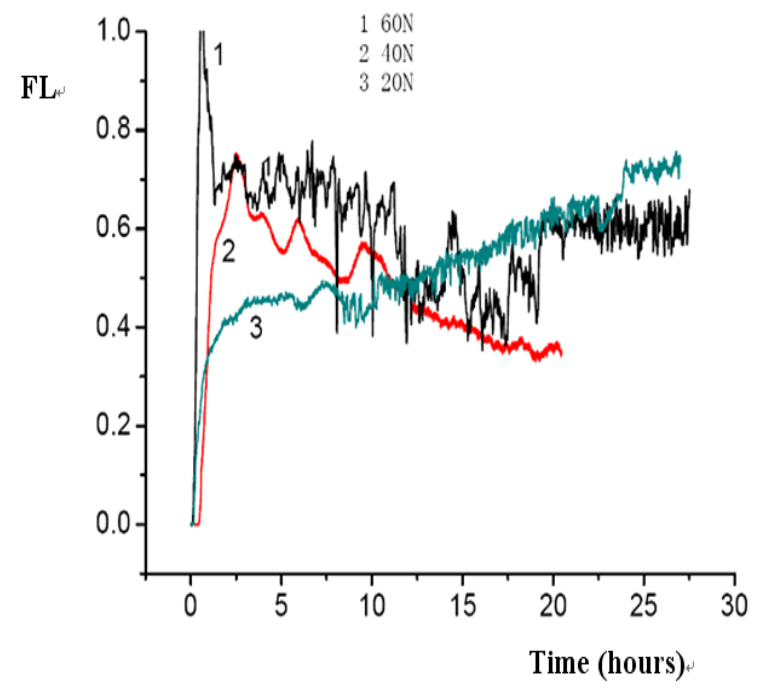

Fig. (4). Liquefaction degree vs. amplitude of dynamic load (No.10 PPT).

Figs. 5 (a,b) shows the change of liquefaction degree in vertical and horizontal directions in centrifugal experiment. It is shown that the development of pore pressure is fast at the upper part of the sand layer because of the big perturbation here. In vertical direction, the liquefaction degree decreases gradually from up to down. The upper part has liquefied (liquefaction degree approach 1.0), while the liquefaction degree of the lower part is only 0.08 .

It indicates that only the upper part of sand layer liquefies and the liquefaction degree decreases along depth under dynamic loads. Similarly, the development of the excess pore pressure decreased fast from near to far away to the sidewall of the bucket. When the load amplitude is $60 \mathrm{~N}$, the sand layer have liquefied at the position $0.2 \mathrm{~m}$ away from the side wall of bucket, while it is only 0.4 at the position $1.4 \mathrm{~m}$ away from the side wall of bucket. Therefore, the ice-induced dynamic load only causes the upper part and near to the bucket side of the sand layer liquefies. This is why the bucket foundation still has big bearing capacity under long-term iceinduced dynamic load.

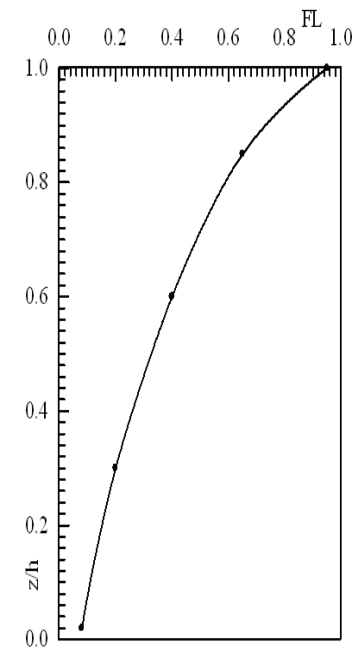

(a) in depth direction

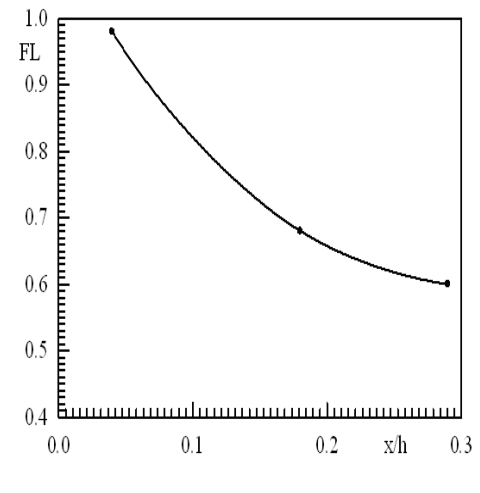

(b) in horizontal direction
Fig. (5). The distribution of liquefaction degree in depth and horizontal direction.

\section{SIMPLIFIED NUMERICAL MODEL OF BUCKET- SOIL INTERACTION}

\section{Simplify of Calculation Model}

Three or two dimensional models were often used to simulate the static and cyclic capacities of bucket-foundation numerically. The interaction between the bucket and soil are simulated by the coulomb friction cell [11-13]. Although this method can reflect simulate static conditions well, the coulomb friction cell is not able to simulate dynamical actions since the direction of dynamic-load is alternative. According to the centrifugal experimental results under dynamic load, the bucket and the sand inside the bucket may be thought as a whole rigid body compared with the sand layer around it. Therefore, the numerical model can be expressed as follows: The sand layer is supposed to be finite in depth but semiinfinite in horizontal direction and the bottom is impermeable. The top of the sand is free. The bottom is vertical restricted. The model sketch shows in Fig. (6).

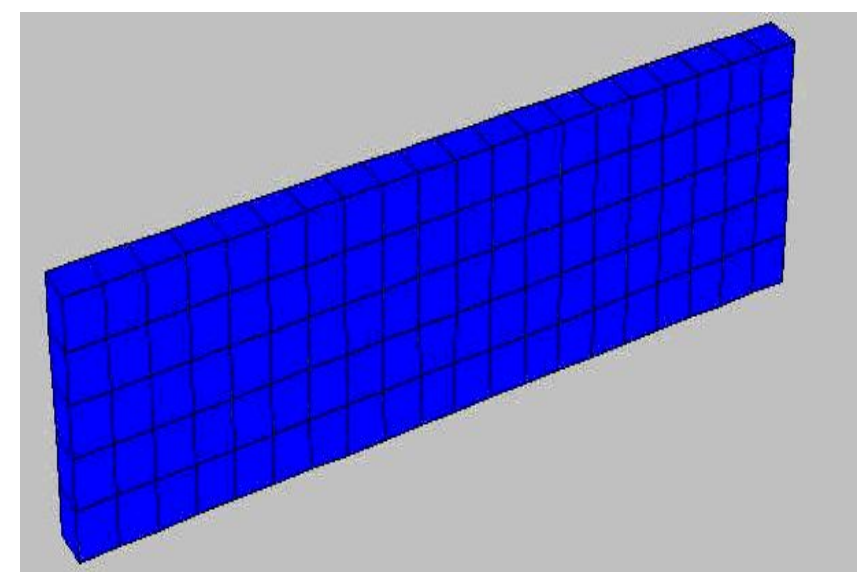

Fig. (6). Numerical model sketch. 
Table 1. Comparison of Liquefaction Degree at Different Positions

\begin{tabular}{|c|c|c|c|c|c|}
\hline \multirow{2}{*}{$\mathbf{z} / \mathbf{h}$} & \multicolumn{2}{|c|}{$F_{l}$ (Vertical Direction) } & \multirow{2}{*}{$x / h$} & \multicolumn{2}{|c|}{$F_{l}$ (Horizontal Direction) } \\
\cline { 2 - 5 } & Test Results & Numerical Results & & Test Results & Numerical Results \\
\hline \hline 0.8 & 0.95 & 0.90 & 0.04 & 1.00 & 0.90 \\
\hline 0.58 & 0.24 & 0.29 & 0.2 & 0.68 & 0.56 \\
\hline 0.42 & 0.10 & 0.18 & 0.29 & 0.60 & 0.55 \\
\hline 0.31 & 0.08 & 0.12 & - & - & - \\
\hline
\end{tabular}

In calculating, according to the plane strain numerical model, the sand layer stress and strain along $x-z$ plane are studied, and the relative depth $(z / h)$ and the relative width $(x / h)$ are used to reflect the dynamic response spread in the depth direction and in horizontal direction of the sand layer.

At first, the initial earth stress is balanced gradually in confining stress state. Then, the left restriction is released (the vertical restriction still on the bottom, the right side is no reflection side). The cyclic load is applied on the left side of the sand. The cyclic load is taken as an equivalent sine wave which has certain frequency and amplitude act on the left side of the sand layer. According to the load condition in the centrifugal experiments, the load frequency is $1.0 \mathrm{~Hz}$, and the load amplitude whose effects are equivalent to a linear displacement function, the maximum amplitude is $16 \mathrm{~cm}$ on the top of the sand and the minimum is zero on the bottom.

\section{Parameters Adopted in the Numerical Simulation}

The saturated sand layer is thought to be two-phase media: sand skeleton and pore water. According to dynamic calculation coupling fluid motion condition, the initial waterhead is zero at the top surface of sand layer. It is impermeable at the bottom. The pore water pressure increases linearly along depth and the sand skeleton is incompressible. During the calculation for initial earth stress balance, the mohrCoulomb model is adopted for sand skeleton. According to the results of cyclic triaxial experiments, the sand layer's elasticity modulus is $4.0 \times 10^{7} \mathrm{~Pa}$, the Poisson's ratio is 0.35 , the internal friction angle is $36.5^{\circ}$, and the density is $1600 \mathrm{~kg} / \mathrm{m}^{3}$.

During the calculation for the interaction of two-phase media, the sand skeleton is assumed obey the Finn model, and the pore water is assumed isotropy elastic. The Biot coefficient is 1.0 , permeability coefficient is $1.0 \times 10^{-6} \mathrm{~cm} / \mathrm{s}$, the bulk modulus of pore water is $2.0 \times 10^{9} \mathrm{~Pa}$, porosity ratio is 0.40 and the relative density of saturated sand is 0.54 [16].

According to the Finn model, the strain increment is calculated using Byrne equation, which is expressed as Eq.(1) Eq.(3).

$\Delta \varepsilon_{v d}=c_{1} \gamma \exp \left(-c_{2}\left(\varepsilon_{v d} / \gamma\right)\right)$

$c_{1}=7.6 \times 10^{3}(D r)^{-2.5}$

$c_{2}=\frac{0.4}{c_{1}}$ in which $\Delta \varepsilon_{v d}$ is the volume increment, $\gamma$ is the maximum cyclic shear strain, $c_{1}$ and $c_{2}$ are the constants, $D_{r}$ is the relative density of sand.

\section{Comparison of the Numerical and Experimental Results}

To compare the numerical with experimental results, the load conditions and initial and boundary condition are adopted according to the centrifuge experiments. The comparison of the liquefaction degree at different positions is shown in Table 1. It is shown that the numerical results are close with centrifuge experimental results. So, the numerical model is reliable.

\section{Expansion of Liquefaction Zone}

An horizontal dynamic load (load frequency is $1.0 \mathrm{~Hz}$, amplitude changes linearly along depth, on the top surface is $16 \mathrm{~cm}$, on the bottom is zero) is applied on the left side of sand layer. Simulation of the expansion of liquefied zone and the changes of liquefaction degree is carried out. The changes of liquefaction degree along depth and with distance from the load side are shown in Fig. (7). From the Fig. (7a), we can see that the liquefaction degree decreases gradually from top to bottom of sand layer. When the horizontal dynamic load describing in this paper acts on the sand layer, the maximum liquefaction degree is 0.9 at the top of sand layer $(x=0, z=h)$, and liquefaction degree is only 0.06 at the bottom $(x=0, z=0.2 h)$. In the range of $0.6 h \leq z \leq h$, the liquefaction degree is relatively greater. From Fig. (7b), we can see that the liquefaction degree decreases gradually with the increase of distance from the load side, after $x>0.85 h$, the liquefaction degree decreases rapidly. For example, the liquefaction degree is only 0.01 when $x=h, z=h$. After $x>3.0 h$, the effects of dynamic load can be neglect. Therefore, when horizontal dynamic load(load frequency is $1.0 \mathrm{~Hz}$, amplitude changes linearly along depth, on the top surface is $16 \mathrm{~cm}$, on the bottom is zero) acts on the sand layer, the liquefaction zone in saturated sand layer around bucket foundation is in the range of $0 \leq x \leq 0.85 h, 0.6 h \leq z \leq h$.

\section{EFFECT FACTORS OF LIQUEFACTION DEGREE}

\section{Effects of Dynamic Load's Frequency and Amplitude}

Fig 8(a) is the distribution of liquefaction degree along depth on the load side under different dynamic frequencies for the same dynamic amplitude. We can see that the liquefaction degree decreases gradually along depth. When the load frequency is less than $1.0 \mathrm{~Hz}$, with the increase of fre- 


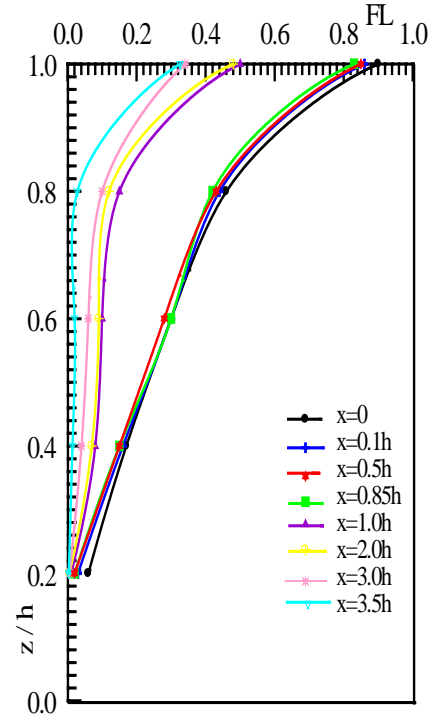

(a)

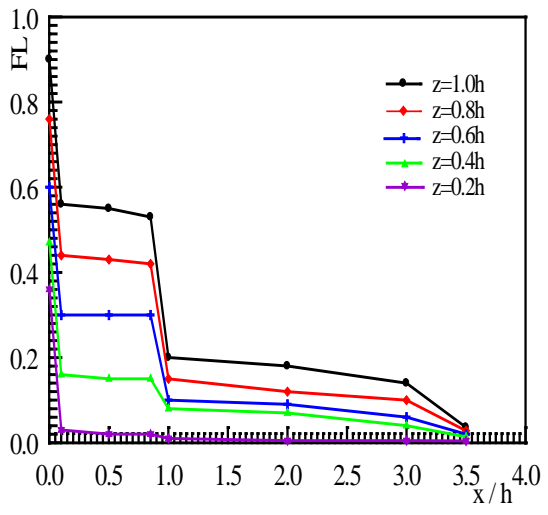

(b)

Fig. (7). Numerical simulating results of liquefaction zone expansion.

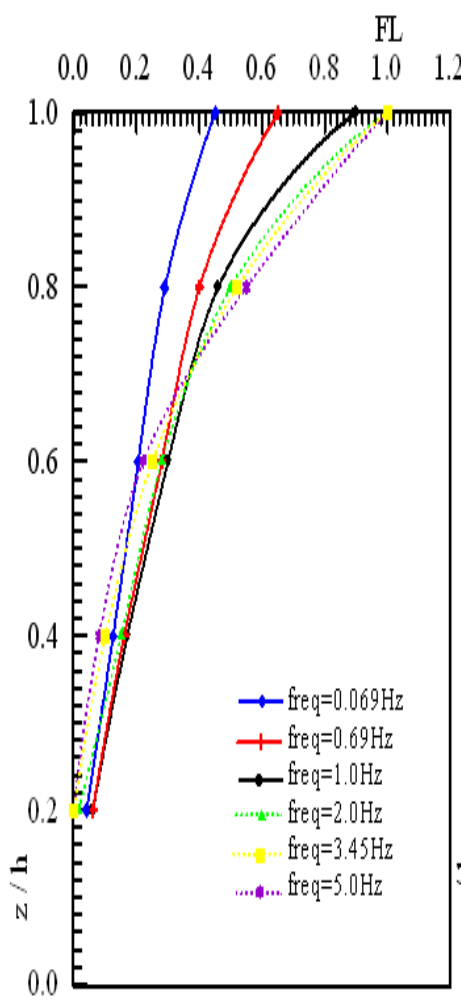

(a)

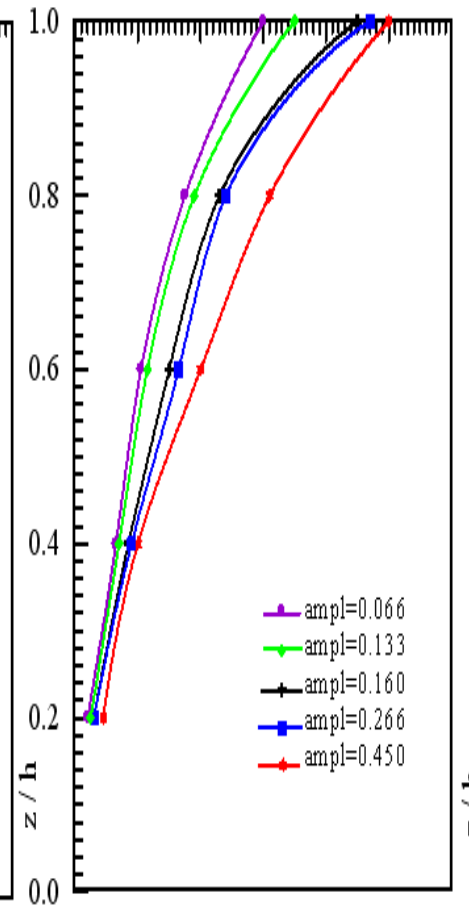

(b)

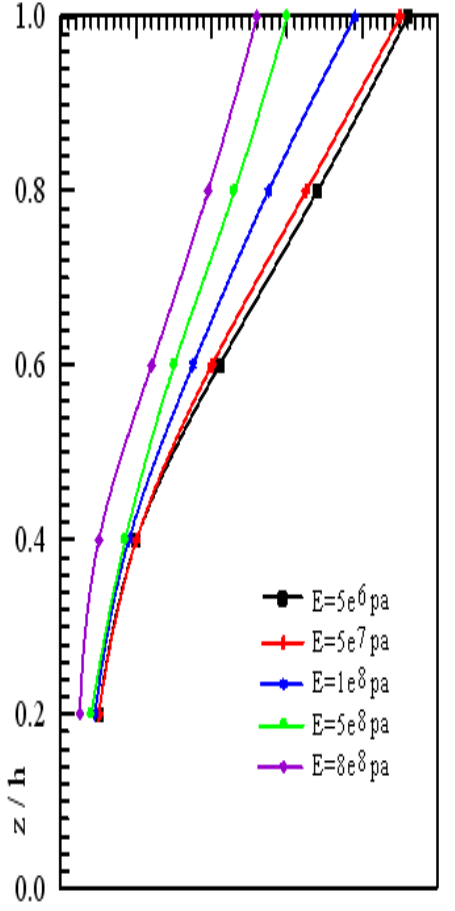

(c)

Fig. (8). Distribution of liquefaction degree and influencing factors.

quency, the excess pore water pressure can accumulate fast, so the sand layer is easy to liquefy. However, when the dynamic-load's frequency is more than $1.0 \mathrm{~Hz}$ (show as the dashed line in Fig. (8a)), the accumulation of the excess pore pressure only appears near the top surface; the liquefaction degree on the bottom surface nears to zero. Fig. (8b) is the distribution of liquefaction degree along depth on the load side under different load amplitudes when the load frequency is $1.0 \mathrm{~Hz}$. It can be seen that the liquefaction degree decreases from top to bottom. In the range of $0.6 h \leq z \leq h$, the liquefaction degree is growing obvious with the increase of load amplitudes.

\section{Effects of Sand Parameters}

Fig. (8c) shows the effects of the elastic modulus of sand skeleton. It can be seen that the excess pore pressure in- 


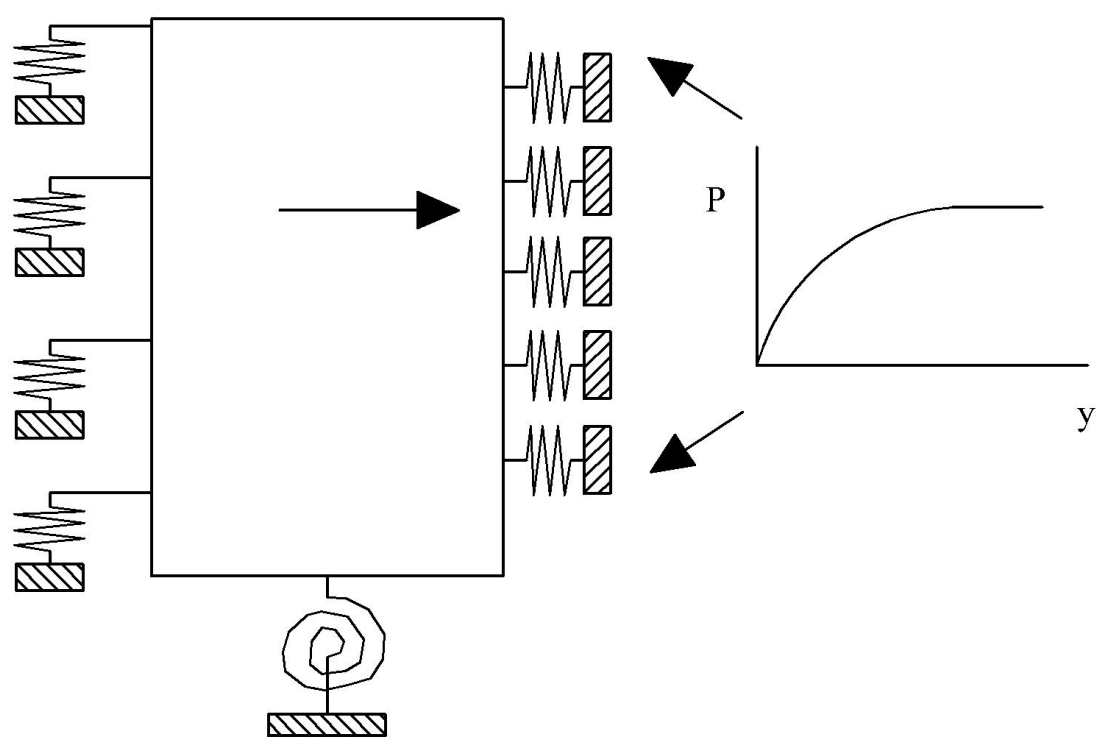

Fig. (9). The simply model of bucket foundation.

creases fast with the decrease of elastic modulus, which causes the fast decrease of the strength of skeleton. For an example, when the elastic modulus decreases from $5.0 \times 10^{7} \mathrm{~Pa}$ to $5.0 \times 10^{8} \mathrm{~Pa}$, the liquefaction degree on the top surface will increase rapidly from 0.6 to 0.9 .

\section{CAPACITY DEGRADATION RULES OF BUCKET FOUNDATION}

\section{Simplified Calculation Model of Bucket Foundation}

From the analysis above, it can be seen that while a dynamic load is applied on one side of sand layer, the liquefaction degree will decrease from top to bottom with the calculation depth increase. Therefore, the resistance of the sand layer is equivalent to a series of nonlinear springs with different stiffness along the right side of bucket foundation, furthermore, the horizontal damage and the bearing capacity of bucket foundation can be described by $p-y$ curves, and the simplified calculation model is shown in Fig. (9).

The stiffness coefficient is adopted as the sand layer's elastic modulus $\mathrm{E}_{0}$, with which the horizontal bearing capacity of bucket foundation when the sand layer have not liquefied can be determined [17]. The resistance in different depth on the right side of bucket is equivalent to different spring stiffness coefficient which is taken as $\left(1-F_{l}\right) E_{0}\left(F_{l}\right.$ is the liquefaction degree) for liquefied sand layer. Define the degradation degree as the ratio of the capacity of bucket foundation in liquefied sand layer and the bearing capacity of bucket foundation in no-liquefied sand layer.

\section{Numerical Simulation Results}

According to the centrifugal experiments, the bucket diameter is $0.5 \mathrm{~m}$; height $0.5 \mathrm{~m}$, wall thickness is $2 \times 10^{-3} \mathrm{~m}$ in computing. The bucket material is linear elastic steel whose elastic modulus is $2.1 \times 10^{11} \mathrm{~Pa}$ and the Poisson's ratio is 0.25 . Five horizontal spring restrictions are settled on the right side of bucket in order to simulate the horizontal resistance action in different depth on bucket side. The stiffness coefficient in different depth along the bucket side is (1$\left.F_{l}\right) E_{0}$, the liquefaction degree from top to bottom of sand are $0.9,0.46,0.3,0.17,0.06$ respectively for certain dynamic load in this paper. The horizontal bearing capacity of bucket foundation is determined. When the maximal horizontal displacement reaches $0.05 D$ ( $D$ is the bucket diameter). As known, the horizontal bearing capacity of bucket foundation is $4.4 \mathrm{kN}$, the sand layer's elastic modulus $E_{0}$ is $2.6 \times 10^{7} \mathrm{~Pa}$, and the horizontal bearing capacity of bucket foundation is $3.8 \mathrm{kN}$ according to degradation spring model built in this paper.

The calculation results indicate that the degradation degree of bearing capacity of bucket foundation is $12 \%$ while it is $17 \%$ in centrifuge experiments under the same conditions. It indicates that the numerical results by the model presented in this paper are agreement well with that of centrifugal experimental results.

\section{CONCLUSIONS}

Based on the centrifugal experiments, a simplified numerical model of liquefied sand is presented. The expansion of liquefied zone and liquefaction degree under horizontal dynamic load are studied. Furthermore, the resistance of the sand with some liquefaction degree is equivalent to a series of nonlinear springs with different stiffness along the side of bucket foundation. The degradation of the bearing capacity of bucket foundation in liquefied sand layer is computed. 
Simplified model offers a new way to analyze the bearing capacity of bucket foundation in liquefied sand layer.

\section{ACKNOWLEDGEMENT}

This project was supported by the fund of Chinese Ocean Oil Co. and Chinese Academy of Sciences (KJCX2-SWL03-01).

\section{REFERENCES}

[1] P. M. Aas and K. H. Andersen, "Skirted foundation for offshore structure,"In: Ninth Offshore South East Asia Conference, World Trada Center Singapore, Singapore, 1992, pp. 1-7.

[2] L. Sherif and E. I. Gharbawy, "Suction cassion in soft clay," In: Proceeding of the 18th International Conference on Offshore Mechanics and Arctic Engineering, Newfoundland, OMAE99/ OFT4063, 1999, pp. 1-7.

[3] T. L. Tjelta, J. Hermstad and E. Andenaes, "The skirt piled gullfaks c platform installtion,'In: Proceeding of the Offshore Technology Conference, Houston, Texas, OTC6473, 1990, pp. 453-462.

[4] M.F. Randolph and A.R. House, "Analysis of suction cassion capacity in clay," In: Proceeding of the Offshore Technology Conference, Houston, OTC 14236, 2002, pp. 1-11.

[5] J. H. Prevest, "Mathematical modelliing of monotonic and cyclic undrained clay behavior," International Journal for Numerical and Analytical Methods in Gemechanics, Vol. 1, No. 1, pp. 195-216, April 1981.

[6] W.A. Marr and J. T. Christian, "Permanent displacements due to cyclic wave loading," Journal of Geotechnical Engineering, ASCE, Vol. 107, No. GT8, pp. 129-1149, August 1981.

[7] K. H. Andersen and R. Lauritzsen, "Bearing capacity for foundations with cyclic loads," Journal of Geotechnical Engineering, Vol. 114, No. 5, pp. 540-555, May 1988.
[8] K. H. Andersen and R. Dyvik, "Field experiment of anchors in clay II: Predictions and interpretation". Journal of Geotechnical Engineering, Vol. 119, No. 10, 1514-1549, February 1993.

[9] D. N. Cathie, "A soil model for the evaluation of displacement and pore pressures in foundation of offshore gravity structures subjected to cyclic loading," In: International Symposium on Numerical Models in Geomechanics, 1982, pp. 368-376.

[10] J. H. Wang, Z. W. Liu and Y. F. Liu "Estimation of undrained bearing capacity for offshore soft foundation with cyclic loads," China Ocean Engineering, Vol. 12, No. 5, pp. 213-222, February 1998.

[11] J. H. Wang, C. Li and K. Moran, "Cyclic undrained behavior of soft clays and cyclic bearing capacity of a single bucket foundation," In: Proceeding of the 15th International Offshore and Polar Engineering Conference, Seoul, 2005, pp. 392-399.

[12] C. Li, J. H. Wang, and Z. W. Liu, "Cyclic bearing capacity of single bucket foundation on soft clay layer," Journal of Geotechnical Engineering, Vol. 27, No. 9, pp. 1040-1044, September 2005.

[13] C. Li, J. H. Wang and M. L. Shi, "Experimental studies of cyclic bearing capacity character on saturated soft clay layer," Transactions of Tianjin University, Vol. 12, No. 2, pp. 137-141, July 2006.

[14] X. B. Lu, Z. M. Zheng and J. L. Zhang, "Progress in: the study on the bucket foundation of offshore platform," Advances in Mechanics, Vol. 33, No. 1, pp. 27-40, January 2003.

[15] Y. H. Wang, X. B. Lu and S. Y. Wang, "The response of bucket foundation under horizontal dynamic loading," Ocean Engineering, Vol. 33, No. 7, pp. 964-973, July 2006.

[16] J. H. Zhang, G. L. Sun and D. Yan, "Geotechnical centrifuge modeling on suction caissons in offshore engineering," Ocean engineering, Vol. 22, No. 2, pp. 90-97, February 2004.

[17] K. H. Andersen, M. F. Randolph and J. D. Murff, "Deepwater anchor design practice phase report to API/deepstar," The Norwegian Geotechnical Institute and The Centre for Offshore Foundation Systems and The Offshore Technology Research Center, December 2003.

(C) Li et al.; Licensee Bentham Open.

This is an open access article licensed under the terms of the Creative Commons Attribution Non-Commercial License (http://creativecommons.org/licenses/by-nc/3.0/) which permits unrestricted, non-commercial use, distribution and reproduction in any medium, provided the work is properly cited. 